\title{
JUDÍOS Y MOROS EN ARANDA DE DUERO Y SUS CONTORNOS
}

INOCENCIO CADIÑANOS BARDECI

\section{ARANDA DE Duero, CAPITAL DE la Ribera}

La judería y morería arandina han sido una palpable realidad histórica, e incluso urbanística, casi completamente desconocida hasta ahora a pesar de una abundante documentación. Esto explica la escasa importancia que los historiadores locales han otorgado a esta clase social marginada y ante cuya innegable existencia se han mostrado incrédulos, tachándolo de "noticias sorprendentes" '.

La ancha y feraz ribera burgalesa del Duero (unas 12.500 hectáreas) tiene por capital a Aranda, sucesora en esta función de la antigua Clunia. Aranda es, claramente, una de las poblaciones que más deben a su emplazamiento. Allí se inicia la vega del río. Por ser el último punto vadeable, confluyeron en la villa una serie de caminos en forma radial, todos importantes, especialmente el que sigue la margen derecha y que aquí se cruza con el opuesto que desde Madrid se dirige a Francia.

La situación de la villa en el extremo sur de la provincia explica el que, al igual que Miranda de Ebro, se convirtiera en subcapital administrativa y económica de la comarca. Su prosperidad se ha debido a una serie de coincidencias: un emplazamiento intermedio entre capitales de varias provincias, una rica viticultura en cuyo comercio destacaron los judíos, y paso obligado de la densa red de cañadas de la Mesta, base de la riqueza ganadera y lanar que desarrollaría una intensa actividad textil bien patente en la documentación relacionada con moros y judíos.

La historia de la villa es relativamente moderna pues arranca a mediados del siglo XI. Su época dorada lo fue la segunda mitad del

' P. SAnz Abad, Historia de Aranda de Duero. Burgos 1975, p. 112. S. Velasco, Aranda, memorias de mi villa y de mi parroquia. Madrid 1925. 
siglo XV como lo constatan sus edificios más notables. Son los años en que sus calles y mercados se verán transitados no sólo por los monarcas sino, sobre todo, por numerosa población mora y judía atraída por un activo comercio, propio de una crecida población que se halla protegida por una fuerte muralla y dedicada en buena parte a la artesanía ${ }^{2}$.

\section{LA JUDERÍA}

\section{Datos históricos}

La judería arandina no suena hasta muy tarde, en el siglo XIV, y es que antes no debió de existir o ser muy reducido el número de hebreos en la villa. No aparecen contribuyendo hasta fines del siglo $\mathrm{XV}$, lo que resulta muy significativo. Cabría pensar si la judería no fue resultado de una emigración desde las tan atacadas aljamas de Burgos o Belorado. Frente a lo dicho, la presencia de judíos en los pueblos del contorno es muy temprana. En el fuero de Sepúlveda (después aplicado a Aranda) se ordena

«qui vinier a estas ferias, christiano o moro o iudio, venga seguramente».

En Huerta del Rey se les cita en 1137

«tan iudeis quam christianis».

Diez años después vuelve a citárseles en el fuero de Lerma.

La primera vez que aparecen los judíos en Aranda es en relación con su comercio. Al ser el sábado día festivo para los hebreos, Alfonso XI trasladó el mercado al lunes, con el fin de facilitar su asistencia:

"Sepades que el Concejo de Aranda me enviaron mostrar como ellos tienen en Aranda mercado en sabado ... e porque no pueden librar ninguna cosa con los judios e por esta razon pierden mucho de lo suyo e se estorvan mucho ellos e los del termino, enviaronme pedir por merced que tuviese por bien de darles mercados en lunes y yo tuvelo por bien ... ca mi voluntad es que el dicho logar de

${ }^{2}$ I. Cadinanos BaRdecI, Arquitectura fortificada en la provincia de Burgos. Madrid 1987, p. 338. 
Aranda se pueble asi de cristianos como de judios en manera que puedan pasar los unos con los otros..." (6-mayo-1326) ${ }^{3}$.

A juzgar por el repartimiento de 1474 la judería arandina era equivalente a la de Coruña del Conde, que posteriormente la superaría notablemente. Con todo, la de Aranda sería siempre bastante más numerosa que las demás aljamas del contorno. Hacia el año 1480 entra en crisis, pues mientras que estas últimas se mantienen casi estacionarias, la de Aranda, por el contrario, inicia un claro descenso. Son años malos, aunque los historiadores locales den a entender, enfáticamente, lo contrario. Ni los arandinos se entregaron voluntariamente a los Reyes Católicos, ni su recuerdo debió de ser tan positivo cuando serán, precisamente, sus habitantes los que más se opusieron al Emperador con ocasión de las Comunidades. Concretamente a comienzos del año 1480 se producen ciertos alborotos por incumplimiento de las ordenanzas otorgadas por la reina doña Juana, su señora. Sus quejas ante el Consejo Real se resumían en que

"a cavsa de aquella mala gouernaçion e regimiento e por los grandes males que la dicha villa ha reçebido asy de los yelos e secas que dis que han perdido los frutos de los grandes gastos ... estauan mucho fatigados».

Frente a las juderías del norte burgalés, de fuerte crecimiento hasta la expulsión, estas de la parte meridional se mantuvieron a duras penas hasta el punto de que en el quinquenio anterior a dicha expulsión la diferencia en número y posibilidades económicas con cualquiera de aquéllas es claramente inferior. La crisis fue paralela a la de las juderías tan castigadas de Pancorbo y Miranda de Ebro.

De las justicias locales dependió el conocimiento de las contiendas suscitadas tanto en la propia aljama como con la comunidad cristiana. Ejemplo de lo primero es cuando el 4 de julio de 1476 el Consejo Real encargaba al alcalde local hacer justicia a petición de Yuda de Soto que se quejaba de

"como Jacob de Soto su padre fallesçio desta presente vida e que suçedieron en su herençia el dicho Yuda de Soto e Simuel e Abrahan de Soto sus hermanos e que al tiempo quel dicho su padre fallesçio el dicho Abrahan estaua de continuo de biuienda en casa del dicho

\footnotetext{
${ }^{3}$ S. Velasco, Aranda, p. 61.
} 


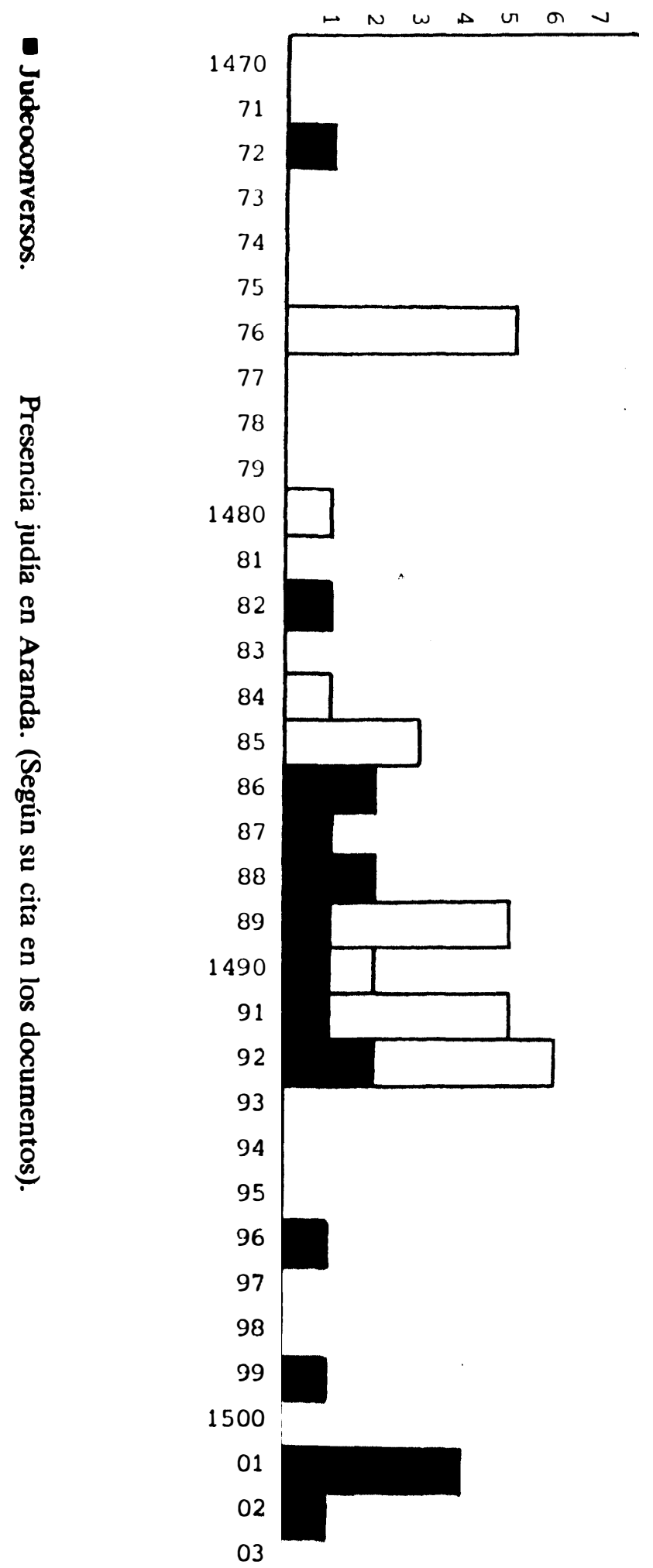


su padre e se alço con muchas joyas de oro e de plata e escripturas christianas e judiegas ... e el dicho Abrahan asy alçado con todos los dichos bienes e escripturas ha fecho grandes ynfyntas e encubiertas en los dichos bienes en espeçial dando algunos contratos de los que estauan fechos e çelebrados al dicho su padre e cuyos son e faziendoles que fagan a el otros de nuevo porque les fase alguna quita de las dichas debdas que deuen ... e asy mismo que Symuel de Soto su hermano dis que fue testamentario e tenedor de çiertos bienes de sus sobrinos fijos de Salomon de Soto su hermano ... e que estan en poder del dicho Symuel...".

Pero no siempre fue así pues los Reyes también escucharon las apelaciones que dirigieron los judíos arandinos ante el Consejo Real en casos de injusticia notoria. Ejemplos podrían ponerse muchos, como el que en 1485 enfrentaba a Bienvenida judía, mujer de Yuçe de Soto, con cierta cristiana de la localidad.

A pesar de la fuerza social y económica de la judería y de su localización casi independiente, no siempre debieron de estar seguros sus miembros de no ser asaltados, robados y hasta asesinados. Parece demostrarse así de ciertos seguros reales como el que los Reyes Católicos otorgaban en 1490 a

«Raby Yuçe aven Santo judio nuestro arrendador e recabdador mayor de las alcavalas e terçias de la merindad de Villadiego ... para que por tiempo de quinze dias primeros ... pueda venir a la dicha villa de Aranda a estar en ella durante el dicho tienpo..." 4 .

Finalmente hay que dejar constancia de cómo a través de las actividades que a continuación se relatan puede constatarse una cierta estratificación social en función de los bienes poseídos. Quizá pudieran ser, también, una muestra de ello los casos en que la documentación trata de "don" a unos y no lo hace con el resto.

\section{Actividades de los judios arandinos}

Cuando los judíos se concentran en las calles de Barrionuevo y del Pozo consta que no sólo eran propietarios de sus casas sino que, además, tenían en ellas grandes bodegas

«las más antiguas de Aranda y de mejor ver».

\footnotetext{
${ }^{4}$ R(egistro) G(eneral) del S(ello). T. I, $n^{2}$ 1.330; T. II, $n^{2} 2.690$; T. IV, $n^{\circ} 883$ y T. VII, $\mathrm{n}^{\mathrm{Q}} 3.792$.
} 
Al retirarse del centro de la villa continuaron siendo propietarios de las casas que ocupaban. Así se deduce de algunos documentos. En 1489 los Reyes exigían al vicario de Osma que les remitiese el proceso que había incoado en el pleito habido entre algunos vecinos de Aranda con Bienvenida

"sobre unas casas que son en la dicha villa al barrio de Sant Juan"

Durante los meses precedentes a la expulsión un vecino exigía a Yuçe de Soto

"çierta quantia de maravedis [en concreto, 36.000] por los quales diz que le obligo y ipoteco vnas casas que son al barrio de Cascajal».

y que se negaba a entregarlas

"diziendo que las dichas casas estan obligas al docte de su muger" 5 .

Es más que probable que los judíos se dedicaran al comercio del vino a gran escala. Así hay que deducirlo de la existencia de las antes mencionadas bodegas (que tan sólo en la calle del Pozo eran unas 43) cuyas cubas disponían de una capacidad que sobrepasaba las 8.000 cántaras. Este vino se vendía en la cercana puerta de Calicanto, posiblemente la conocida también como del Cascajar.

Otros documentos insisten en la citada actividad comercial. Así, en 1480 los Reyes Católicos ordenaban al concejo arandino que abonase a Abrahan Bienveniste cierta cantidad de trigo que le había prestado. Una década después un vecino obtenía una carta de espera de los 2.300 maravedís que adeudaba al judío Rabí Ça,

"persona rico e cabdaloso",

a quien se los debía por haberle comprado cierta cantidad de pan y vino, a cuyo comercio se dedicaba ${ }^{6}$.

El vino fue la principal riqueza de Aranda, como constantemente repiten los documentos. Pero no significa que fuera una villa rica. La falta de suficiente terrazgo dedicado al cereal, agravada por los espacios incultos aprovechados por la Mesta, unidas a otras muchas causas como el absentismo, la alta actividad artesanal cuyos individuos debieron de rayar el límite de la mera subsistencia, el gran consumo de una villa muy transitada, los constantes servicios ex-

${ }^{5}$ RGS. T. VI, $\mathrm{n}^{2} 1.563$.

${ }^{6}$ RGS. T. VII, $\mathrm{n}^{9} 4.063$. 
traordinarios de las guerras, las escasas y generales malas cosechas de la época $\mathrm{y}$, en general, la inadecuación del sistema económico todavía medieval a la moderna situación social, favorecieron la práctica judía ( $\mathrm{y}$, en algún caso, también cristiana) de la usura. La documentación nos ha dejado buena constancia de ello.

En 1478 los Reyes Católicos comisionaban a Martín Fernández de la Plaza para que entendiese en las querellas sobre usuras que ciertos concejos tenían con diferentes judíos, aunque no pudo resolver nada. Por ello, un año después los monarcas ordenaban a los jueces eclesiásticos de Osma que levantasen las excomuniones pronunciadas contra los deudores de los judíos y no entendiesen en esta causa. Entre los pueblos afectados estaban Arauzo de la Miel y Huerta del Rey. Las quejas provenían de los

"grandes males, robos e sinrazones"

que los judíos de diversas aljamas, entre ellas Aranda, Roa, Coruña del Conde y Peñaranda, les hacían

«en rason de çiertos contratos e obligaciones ... cargadas a muy mayores presçios por los dichos judíos"

aprovechándose de los difíciles momentos de la guerra y

"de los años estirados de pan».

En 1489 los Reyes denegaban una segunda carta de espera a dos vecinos de Aranda en la deuda pendiente con cierto judío de Segovia. Los endeudados debieron de pasar en algunas ocasiones verdaderos apuros para devolver los préstamos. En 1489 los monarcas ordenaban a las justicias de Aranda que designasen algunas personas que apreciaran los bienes raíces de Francisco de Peñafiel por un monto de 22.000 maravedís, cantidad que debía a Samuel de Soto. Pocò después concedían una carta de espera a Martín de Tamayo, hombre pobre y menesteroso, en razón de los 5.400 maravedís que debía a doña Ça, judía de Aranda. El año precedente a la expulsión se comisionaba al bachiller Alonso de Torres para que entendiese en las quejas de usura presentadas contra ciertos judíos de Coruña del Conde, Peñaranda, Gumiel del Mercado, Aranda, Roa y Torregalindo por campesinos de diferentes lugares de la comarca pues

«les lievan muchas quantias de maravedis de logros e usuras e relançes e de otras cosas yliçitas e proybidas» 
con la anuencia de las justicias de los pueblos en que moraban dichos judíos.

Incluso bastante después de la expulsión seguían existiendo quejas y problemas por cuestiones de usura. A comienzos del año 1494

"el concejo e omes buenos del logar de Moradilla e el aldea de Sotiio, que es en el obispado de Osma, nos fizieron relacion ... que en el tienpo de los movimientos pasados en la guerra que touimos con el rey de Portogal fueron quemados los dichos logares en la qual quema que se quemaron mas de treynta pares de casas con toda la fazienda que estaba dentro en ellas e que el dicho logar e la mayor parte de los vecinos del quedaron perdidos e pobres ... tomaron prestados a logro ... de don Symuel».

Como no le pagaron a su tiempo

"les leuo de logro e cohechos diez e seys mill maravedis e çiertos carneros e cabrones e canastos de miel e muchas gallinas",

por lo que fue preso. Al marchar del reino, traspasó parte de sus deudas a ciertos fiadores que para cobrar a los lugareños empleaban métodos parecidos a los del judío ?.

En alguna ocasión consta también que los judíos fueron deudores de algún vecino de Aranda ${ }^{8}$. En ésta pueden constatarse dos tipos de recaudadores: los de la Hacienda Pública, que suelen ser judíos segovianos, y los locales, que se encargaron de las recaudaciones del concejo arandino.

En 1481 el cobro de impuestos de la región estaba en manos de Rabí Mayr Melamed, vecino de Segovia. Cuatro años después los Reyes Católicos ordenaban a la villa que permitiera al arrendador de las alcabalas, pechos y derechos de la villa y tierra, Don Zácaro de Segovia, el poder subastar públicamente las rentas en personas de la villa y su comarca durante tres años por 1.300 .000 maravedís anuales más 11 maravedís el millar y derechos de oficiales por 60.000 maravedís de promedio cada año.

Durante los meses anteriores a la expulsión unos vecinos pleiteaban con Salomon Seneor, natural de Segovia, recaudador de las

${ }^{7}$ Cf. Apéndice 1.

${ }^{8}$ RGS. T. III, $\mathrm{n}^{2}$ 2.206; T. VI, nô 2.276, 2.564 y 2.738; T. XI, $\mathrm{n}^{2}$ 233. L. SUÁREZ FERnÁnDEZ, Documentos acerca de la expulsión de los judios. Valladolid 1964, pp. 134, 149 y 358. 
alcabalas de la villa, sobre cierta deuda. En septiembre del mismo año se sentenciaba a favor de los primeros

«en razón de çiertas rentas que los dichos ... ouieron puesto en preçio en la dicha villa de Aranda para en este presente año de noventa e dos e para los dos años adelante venideros de noventa e tres e noventa e cuatro años los quales dis que fueron rematados en ellos por Lezar Cardero hazedor del dicho Don Salamon Señeor sobre...".

las rentas del peso, haba, mosto, varas, corambre y zapatería 9

Las recaudaciones locales se encargaron a judíos de la villa. Isaac Bienveniste pleiteaba con la villa en 1485 por el remate de una renta que se hizo en perjuicio suyo puesto que antes se le había arrendado las rentas de los comunes de la villa por 40.000 maravedís. La actuación del recaudador Don Yuçe de Soto estuvo llena de sobresaltos. A comienzos del año 1484 se le acusaba de no querer pagar una deuda de $\mathbf{4 0 . 0 0 0 ~ m a r a v e d i ́ s ~ y ~ p a r a ~ e l l o ~}$

"fuyo e se absento de la dicha villa"

pero se ejecutó

"en dos pares de casas del dicho judio".

Exactamente un año después consta

"que estando en la carçel publica ... asas tienpo ... don Yuça por çiertas debdas a çiertas personas vesinos de la dicha villa de Aranda”

se fugó quebrantando las cadenas, por lo que los Reyes ordenaron su captura. Fue hallado poco después, pero no pudo apresársele. Mandaron vender sus bienes muebles con los que pagar la extraordinaria cantidad de 110.000 maravedís que adeudaba a un recaudador cristiano de las tercias de la villa, correspondientes a los años 1481 y 1482. Incluso se apresaron y secuestraron los bienes de Doña Bienvenida, su mujer, a petición de Catalina González con quien tenía arrendadas las rentas pontificales del año precedente. Por todas partes aparecían deudas, pues, unos meses después, otro arrendador le exigía 100.000 maravedís

${ }^{9}$ RGS. T. IV, n 234; T. IX, nes 1.801 y 3.057. M. HuRTADO, Colección diplomática del archivo histórico municipal de Aranda de Duero. Documentos reales (siglos XIII al $X V I)$. Burgos 1986, p. XIX y $\mathrm{n}^{2} 18$. 
"de çiertas nuestras rentas"

del año 1481. Incluso años más tarde, poco antes de la expulsión, se ordenaba a los alcaldes de Aranda que se obligase al mencionado judío a abonar 20.000 maravedís, una taza de plata, 102 onzas de plata y otras cantidades menores a lo que se oponía

"disyendo que no tiene ninguna fasyenda de que poder pagar ... lo qual dis que fase porque se ha de yr muy prestamente fuera destos nuestros reynos syn le pagar cosa alguna» ${ }^{10}$.

A través de la documentación pueden seguirse otros oficios a los que se dedicaron los judíos arandinos. En 1447 se dice en las actas del Ayuntamiento de Burgos que debía pagarse lo suyo al

«judio çerujano de Aranda».

En 1486 consta que existía una carnicería propia para la aljama judía. En 1491 se enfrentaban ante el Consejo Real doña Mugeruna, judía mujer de Levi vidriero, con doña Vellida, también judía, quejándose de que los alcaldes locales habían dado

"por libre e quita a vos la dicha Mugeruna de çiertos bienes que ella vos avia dado en guarda" ".

Finalmente, hay que dejar constancia de que, según cierto documento del archivo de la catedral de Osma, cada judío de Aranda tenía que pagar al obispo 30 dineros al año. En 1454 las aljamas de Aranda, Roa, Gumiel del Mercado y Coruña del Conde se avinieron a pagar a dicho obispo una cantidad fija de encabezamiento.

\section{El barrio judio y la sinagoga}

La ptimitiva cerca que defendió Aranda abarcó únicamente la parte más occidental de la villa. Cuatro puertas la horadaban. De este a oeste, la Dehesilla y San Juan, y de sur a norte las puertas del Duero y Cascajar. Junto a esta última y aprovechando su tránsito, pero extramuros de ella, se asentó la primera judería. El barrio que allí nació tuvo un desarrollo anárquico, de calles tortuosas, angostas, en cuyas viviendas predominaba el barro con entra-

\footnotetext{
${ }^{10}$ RGS. T. IV, nos $281,477,487,511,794$ y $1.555 ;$ T. IX, nos 1.757 y 1.797.

$"$ RGS. T. IV, $n^{2} 3.215$; T. VIII, $n^{2} 3.164$.
} 
mado de madera. Simultáneamente, al sur, crecía otro barrio comercial.

Para proteger a esta nueva población se amplía la cerca en el siglo XIV, con lo que el espacio protegido de la villa es ahora casi el doble. La puerta de la Dehesilla es retranqueada más al este y una nueva puerta (Santa Cruz) dará acceso a la zona comercial del sudeste. Judíos y mudéjares quedan protegidos, conviviendo con el resto del vecindario.

Cuando en 1480 se les recluye en calles propias, estas clases marginadas se ven alejadas de las puertas, es decir del paso comercial. Pero mientras que los judíos, con su influencia económica, logran que se les abra un portillo (el Hocino o Santa Ana) los moros, por el contrario, quedarán completamente arrinconados en un extremo incomunicado de la villa.

Con la apertura de la Puerta Nueva, que daba acceso a la calle Barrionuevo, hacia el año 1504, el sistema defensivo de Aranda quedará fijado hasta tiempos bien cercanos.

Consta que los judíos vivieron en un principio

"derramados [mezclados] entre los cristianos por todas las calles y barrios"

aunque ocuparon preferentemente las calles de Barrionuevo y del Pozo, y después de Santa Ana o del Hocino. La primera era ancha y gentil, una de las más nobles de la villa, y más tras el apartamiento judío. La segunda, por el contrario, era muy pequeña, angosta y oscura. Diez años después del éxodo judío todavía no moraba vecino alguno y en ella

«se cometen suciedades con mugeres".

Un informe del año 1503 decía que las citadas calles

"solían ser Jodería antes que los judios se pasasen a bibir a la calle que agora se diçe Santa María»,

correspondiente al primer tramo cercano a la iglesia de este nombre en donde comienza la calle del Hocino conocida posteriormente por Santa Ana, hoy Pedraja. Como consecuencia de las leyes de las Cortes de Toledo (1480), a la aljama arandina

«le fue limitado un lugar ... que se llamava Hoçino donde toviesen su juderia e apartamiento el qual dicho lugar que asy les fue 


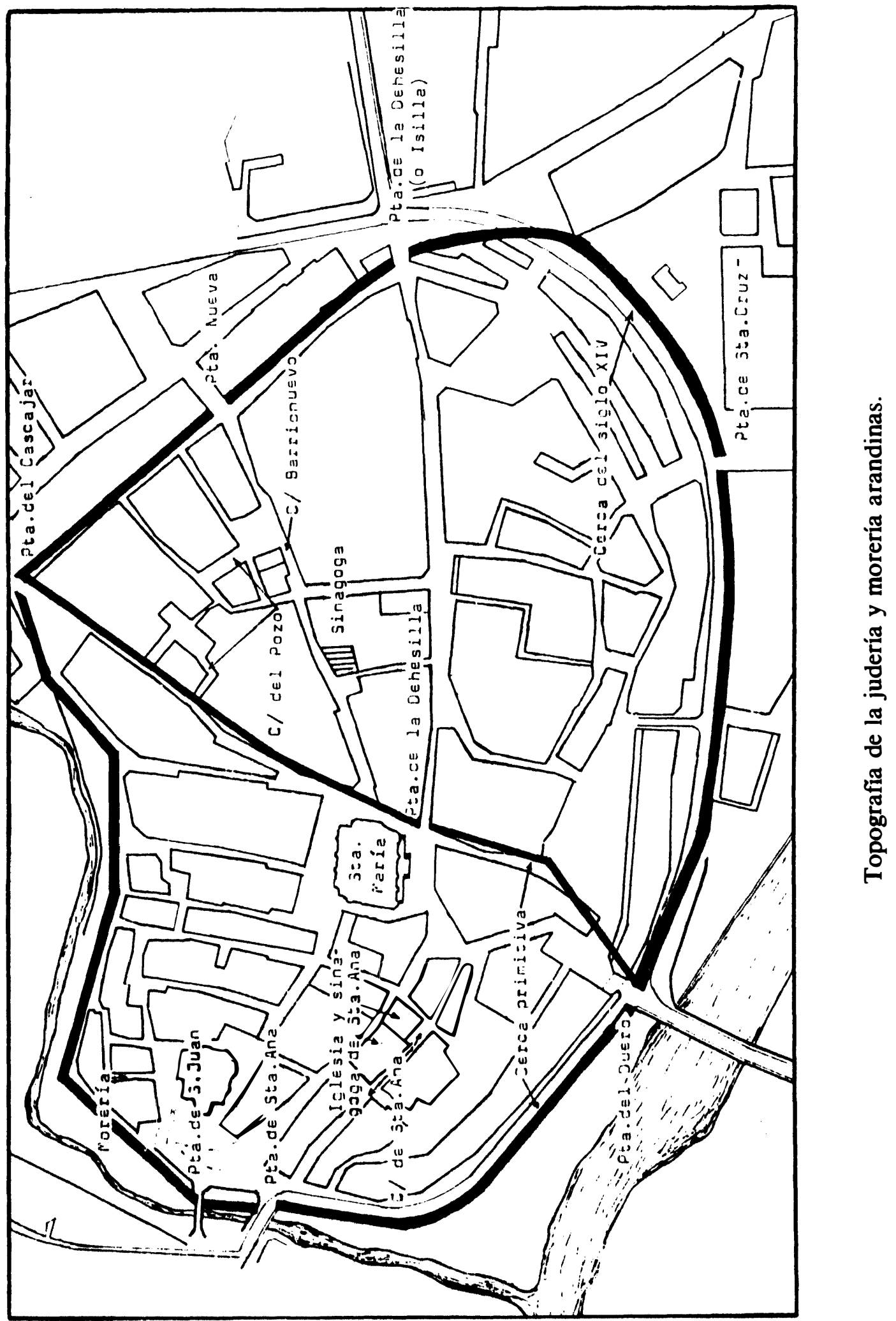


limitado e señalado ... es ynabitable e donde nunca fue poblado nin se espero poblar ... que nos mandasemos abrir un postigo en la çerca ... asy para servidunbre de la dicha juderia como para que por el dicho postigo podiesen manar e salir todas las dichas aguas» ${ }^{12}$.

Con la apertura de este postigo es evidente que también se pretendía favorecer el comercio judío, además de sanear una zona semiabandonada. El nuevo paso (conocido con los nombres de portillo de Santa María o del Hocino o de Santa Ana) acaparó el tránsito procedente de Gumiel del Mercado, Sotillo y Valdesgueva que hasta entonces se había encauzado por la puerta de San Juan. A esto se debe el que por los días de la expulsión los procuradores de esta última calle pretendieran cerrar el portillo con el fin de evitar la competencia comercial. A ello se opusieron ciertos cristianos ( $\mathrm{y}$, seguramente, también conversos) aduciendo ante el Consejo Real evidentes perjuicios ${ }^{13}$.

La sinagoga se halló en Barrionuevo y más concretamente formando esquina con la calle Tamarón. Tras el relegamiento de la aljama en el Hocino, hubo que levantar una nueva sinagoga que estuvo emplazada junto a la iglesia de Santa Ana, es decir en un punto céntrico de dicha calle. En el mes de mayo del año 1492 el comendador Íñigo de Barahona, vecino y regidor de Aranda, se dirigía al Consejo Real asegurando que

"los dichos judios e aljama desa dicha villa le vendieron vna synoga por çierta quantia de maravedis ... y que con liçençia e acuerdo del provisor de Osma que alli se allo presente diz que fizieron alboroto ... e vinieron con vna cruz a la dicha synoga e que por fuerza e contra su voluntad se entraron en la dicha synoga e le despojaron della e la fizieron eglesia» ${ }^{14}$.

Casi un año después la cofradía de Santa Ana que ocupaba la sinagoga, pedía que se averiguase e informase sobre la propiedad de dicho edificio. Al año siguiente los Reyes ordenaban al corregidor de la villa que dejase usar libremente a los cofrades la sinagoga que habían incorporado a la iglesia del mismo nombre ${ }^{15}$.

${ }^{12}$ Cf. Apéndice 2.

${ }^{13}$ L. Mateos Martín, Aranda de Duero, urbanismo, geografla, historia. Burgos 1987, pp. 13 y ss. RGS. T. IV, $\mathrm{n}^{2} 3.213$; T. IX, $\mathrm{n}^{2} 2.288$.

${ }^{14}$ Cf. Apéndice 3.

15 Cf. Apéndice 4. 
Cierto testigo afirmaba, en 1503, que la antigua sinagoga "esta hecha casa buena» ${ }^{16}$.

Se refería a esta de la calle Santa Ana.

\section{La expulsión}

De los numerosos judeoconversos de que tenemos constancia, podría pensarse que los judíos de Aranda y su comarca fueron más acomodaticios que los de otras partes y por ello permanecieron muchos en la villa.

Para resolver los problemas de la expulsión, los Reyes Católicos nombraron a Alfonso de Torres juez comisario en Aranda. A comienzos del mes de mayo del año 1492 se le encomendaba que autorizase al judío Samuel de Soto y sus hijos a cobrar sus deudas en Aranda y otros lugares en bienes raíces, ante la imposibilidad de cumplir los plazos de vencimiento por haber sido decretada su expulsión. Con el fin de evitar las lamentables condiciones y abusos en que marcharon los hebreos, dicho don Samuel

"por sí e en nombre de sus criados e amigos e parientes"

consiguió de los Reyes que les acompañara el citado comisario pues se recelaba de que algunas personas

«los feriran o mataran o tomaran o robaran sus bienes».

El mismo día los Reyes exigían a dicho comisario que juzgara sobre las deudas que tenían con algunos cristianos este judío y sus hijos Rabí Ça y Rabí Mose y que, a pesar de las órdenes reales, no había querido dirimir hasta entonces.

Los problemas sobre pagos no finalizaron con la expulsión sino que se prolongaron unos años más. A fines del año 1493 los Reyes Católicos prohibían a los vicarios del obispado de Osma que se entrometieran en asuntos de deudas embargadas a los judíos acusándoles de que

"ynpedis que non se faga justiçia»

por el corregidor de Aranda que es a quien correspondía este asunto. Unos meses después ordenaban que se cobrasen

${ }^{16}$ RGS. T. IX, n² 1.944; T. X, n² 562; T. XI, $n^{2} 639$. 
"los bienes a debdas que los judíos dexaron en la villa de Aranda e en sus villas e lugares desa comarca",

y su importe fuera ingresado en la Cámara Real.

A fines del año 1494, ciertos vecinos se quejaban de haberse apropiado el fisco de bienes pertenecientes a Samuel de Soto que ahora les pertenecían por compra. Y todavía a comienzos del año siguiente un tal Juan Núñez de Calahorra pedía justicia pues

«avia puesto vna demanda de fasta veynte mill maravedis a vn don Symuel de Soto ... los quales diz que le devya de vnas casas e bodega de çiertas cubas que le llevo de vna devda de çierto logro" ${ }^{17}$.

\section{Los judeoconversos}

La historia de los judeoconversos arandinos la conocemos con detalle gracias a los documentos publicados por C. Carrete Parrondo ${ }^{18}$. Aunque aparecen judaizantes con anterioridad a la expulsión, sin embargo, la mayoría de los casos ventilados por la Inquisición hace referencia a la oposición ideológico-religiosa entre cristianos y judíos. Tras el éxodo, los problemas se reducen casi exclusivamente a la represión de los judaizantes.

Consta que los judíos convertidos siguieron viviendo, como es lógico, en la calle de Santa Ana. Casi todos aparecen ejerciendo un oficio artesano. Algunos de estos tornadizos procedían de Portugal, vueltos por el deseo de cobrar las elevadas deudas que habían dejado. En 1494, por ejemplo, algunos vecinos de Aranda se quejaban ante el Consejo Real porque cierto judío de Segovia, ahora convertido al cristianismo, les reclamaba antiguas deudas. La mayoría de estas conversiones, por ser forzadas, resultaron insinceras $y$, consecuentemente, mezcla de una antigua doctrina muy arraigada teñida de unos nuevos conocimientos cristianos superficiales y hasta fuertemente rechazados interiormente por repugnantes, lo que dio lugar a la actuación de la Inquisición que llegó a quemar a algunos de Aranda y su comarca, hecho que sus correligionarios atribuyeron tanto a testigos falsos como a la codicia de los inquisidores por apoderarse de sus bienes.

${ }^{17}$ RGS. T. IX, nos 1.512 y 1.800 ; T. X, n² 3.041; T. XI, nos 1.424 y 4.093; T. XII, nos 680 y 702.

18 C. Carrete Parrondo, Fontes iudaeorum regni Castellae. T. II, Salamanca 1985. 
Los años mitigaron los roces y se olvidarían las diferencias. En 1531 el visitador diocesano encarecía la obligación de oír misa tanto a conversos como a cristianos viejos o moriscos. Todavía en 1641 cierto testigo aseguraba haber oído decir que los sambenitos de los años 1489, 1490 y 1492, que se guardaban en la iglesia de Santa María de Aranda, correspondían a un Alonso González, platero, y a varios otros relajados, entre ellos el cura de Villalba de Duero. Y agregaba

«es tradiçion muy antigua que en esta villa se celebró el primer aucto de fe de la Ynquisicion en Castilla la Vieja y que casi todos los sanvenitos que están en la dicha yglesia fueron de los penitençiados en este aucto" ${ }^{19}$.

Que hubo quema de herejes por estos años es seguro pues lo atestiguan varios documentos.

Recuerdo de esta comunidad conversa es la permanencia, todavía, en Aranda de un apellido tan judío como lo es el de Soto. Y lejano eco (siglo XVIII) de la tolerancia que propició su convivencia con el resto del vecindario podría ser la actuación del obispo e Inquisidor General, natural de esta villa, don Francisco Pérez de Prado, quien llega a dedicar un extraordinario tratado sobre el judaísmo

«a mis hermanos amados ... los reconciliados por la Inquisición de Sevilla" ${ }^{20}$.

\section{LA MORERIA}

\section{Datos históricos}

Los moros arandinos ocuparon un barrio especial, y también marginal, y por nombramiento real tuvieron justicias propias (alcaldes). Como en otras partes de la provincia (y de España) sus oficios más típicos fueron los de alarifes y herreros. En 1456 el cabildo burgalés pagaba a varios moros la construcción de unas casas. Entre los alarifes se menciona a un Mohamed de Aranda.

En 1485 se quejaba

«Abdalla de Maestre Abida moro ... que de tienpo inmemorial

\footnotetext{
${ }^{19}$ RGS. T. XI, ne 252. AHN. Inq., leg. 1.380 (exp. 12).

${ }^{20}$ BN. R/9.697.
} 
avian los moros de la aljama desa dicha villa han cogido e coge vn alfaqui que los syrua segund e casos de su ley e quando asy el dicho alfaqui cogen le cogen a contentamiento estando de vna concordia para lo coger todos los moros de la dicha aljama".

y, sin embargo, ahora quería imponérseles uno que no les agradaba.

De 1486 a 1494 fue alcalde de la aljama el herrero Maestre Amete de Torres por nombramiento de los Reyes Católicos. Así se lo comunicaban al Concejo arandiho y a la morería el 16 de mayo de 1486:

«Por fazer bien e merced a vos maestre Amete de Torres, herrador, morador en la villa de Aranda de Duero catando vuestra sufiçiençia e abilidad e los seruiçios que nos avedes fecho e fazedes de cada dia e otrosy acatando asy ser complidero a nuestro servicio e al bien e pro comun del aljama de los moros de la dicha villa es nuestra merçed que agora e de aqui adelante para en toda vuestra vida seades nuestro alcalde de los moros de la dicha villa en lo guardar por vacançia de maestre Abdalla de Muño nuestro alcalde que fue de la aljama de los dichos moros por cuanto el dicho maestre Abdalla es muerto ... e podays usar e vseys de dicho ofiçio de nuestro alcalde e lleuar e lleueys todos los derechos e salarios e otras cosas del dicho ofiçio de alcaldia anexos e perteneçientes e que pertenesçer deuen en qualquier manera e gozar de todas las honras e franquezas de que gozaran los otros alcaldes de la dicha aljama».

Su actuación no debió de ser del todo acertada, al menos constan varias quejas sobre ello. Efectivamente, en julio de 1490 unos moros escribían al Consejo Real diciendo que a dicho Amete se le había nombrado con el fin de que conociera en las causas civiles de la aljama, lo cual era contra derecho pues se oponía a las leyes generales del reino. Momentáneamente los Reyes ordenaron que en dichas causas conocieran sólo los alcaldes ordinarios de la villa. Unos meses después se incoaba pleito por parcialidad durante su mandato. Consecuencia de ello fue la petición de un minucioso informe por parte de las justicias locales. Pero debió de serle favorable la sentencia, pues continuó de alcalde hasta su muerte y también administrando justicia aunque en ciertas causas con un "acompañado" como el que pedían el moro Abrahen y sus parientes en 1492, puesto que dicho Amete les era

«muy odioso e sospechoso» 
y, además, recordaban que si acudían ante él era porque así lo querían, pues, según las leyes del reino, también podían apelar ante los alcaldes ordinarios de la villa en dichas causas civiles ${ }^{21}$.

En 1494 los Reyes volvían a nombrar nuevo alcalde de la aljama en la persona de Yuça, por muerte del anterior. En 1496 Ysmael de Barrio e maestre Mahoma de Corral y otros moros se quejaban ante el Consejo Real de que también este alcalde les resultaba en sus pleitos

"odioso e sospechoso e vos mostrays muy favorable a las otras partes"

por lo que suplicaban que se le obligara a tomar como "acompañado" al corregidor o algún alcalde de la villa ${ }^{22}$.

Ladero Quesada ha evaluado el número de familias mudéjares arandinas en el siguiente número:

1495: 29 familias.

1498: 37 familias.

1499 a 1501: 40 familias, lo que, al convertirse obligatoriamente en 1502, equivaldría a unos 200 nuevos habitantes moriscos sobre una población absoluta de unos 1.500 vecinos.

$\mathrm{Su}$ conversión venía siendo forzada desde tiempo atrás. En el año 1500 los Reyes Católicos tenían que proteger a los mudéjares locales porque se les obligaba a asistir a las predicaciones de las iglesias de Santa María y San Francisco. Cierto fraile de este último convento destacaba por su fanatismo, amenazándoles con ir

«a pedricar dentro de su almagid o morería e que a cabsa que la dicha villa es prinçipalmente poblada de labradores e gente comun, estan los dichos sus partes en gran peligro cada vez que salen e los fazen ayuntar, e diz que por esta cabsa muchos de los dichos moros se han ydo e quieren yr a logares de señorios".

Frente a la protección de la nobleza, contrasta la intolerancia del pueblo bajo para con estos sectores no cristianos exigiendo que

"los dichos moros han de ser christianos quieran o no".

La presión debía de ser fuerte, y por consiguiente la emigración a otros lugares, pues los monarcas volvían a escribir al corregidor

${ }^{21}$ Cf. Apéndice 5.

22 Cf. Apéndice 6. 
arandino un mes después ordenándole que permitiera vender sus bienes a todos los moros que lo desearan hacer ${ }^{23}$.

Las conversiones y el paso de los años absorbió a esta clase marginada dentro del resto del vecindario arandino con quien parece que nunca tuvo graves roces. En alguna ocasión consta que alguna prostituta cristiana acudía a la morería a ganarse el jornal. En 1499 los documentos citan al moro Ydan de Torres, herrador, y en 1533 a un morisco llamado Carrillo. La lista de conversos que nos proporciona la Inquisición en 1594 se reduce a escasas familias:

"Catalina Ruiz, viuda; Juan López, casado con hija de la dicha Catalina Ruiz; María Ruiz, su mujer; Juan López, su hijo; María López, otra su hija; Benito Ruiz, hijo de la dicha Catalina Ruiz; Ysabel de Linares, madre del dicho Juan López, biuda. Çebrián López, que antes se llamaba Çebrián de Linares, hijo de la dicha Ysabel de Linares; Angela de Toledo; Luisa Hernández, biuda» ${ }^{24}$.

\section{El barrio moro}

También la aljama mora, como la judía, vivió en un principio mezclada con los cristianos. En 1480 los Reyes Católicos les obligaban a retirarse a un barrio y calle propios, tras la iglesia de San Juan, una de las zonas más abruptas, insanas y, probablemente, abandonadas de la villa, a orillas del riachuelo Bañuelos. El nuevo emplazamiento era motivo de quejas en 1483. Tres años más tarde los Reyes escribían a cierto pesquisidor diciéndole que la aljama

«nos fizo relaçion ... diziendo que al tiempo que Nos mandamos façer apartamiento de los judios e moros ... fue a la dicha villa por vezinador e para fazer los dichos apartamientos Juan Ortega de Carrion, el qual dis que les senalo lugar para el dicho apartamiento fuera de la dicha villa en el arraval de Duero, el qual con sus gastos e fatygas dis que an fecho sus casas e que la calle que les fue senalada para el dicho apartamiento es calle publica por donde pueden entrar e salyr a la dicha villa los viandantes, que vos fuystes agora por pesquisidor al dicho ... [y debido a cierta información falsa] ... aveys mandado çerrar la calle por amos cabos de manera

${ }^{23}$ M. A. LADERo Quesada, Los mudéjares de Castilla en tiempos de Isabel I. Valladolid 1969, pp. 17, 245 y 251.

${ }^{24}$ AHN. Inq., leg. 2.109; T. IV, nos 1.701 y 3.042; T. VII, nos $2.273,2.838$ y $2.845 ;$ T. IX, $n^{2}$ 2.012; T. XI, $n^{\circ} 449$; T. XIII, $n^{\circ} 1.285$. 
que por la dicha calle nin por las puertas que dexareys non pueden entrar libremente carretas nin bestias cargadas".

La aljama le había pedido que pusiera remedio, pero no quiso hacerlo. Los Reyes le ordenaron que

"deseys en la dicha morería dos puertas grandes por donde puedan entrar carretas e bestias cargadas para sus neçesydades",

pero tampoco obedeció puesto que un mes más tarde volvían a reiterar la orden ${ }^{25}$.

Algún moro siguió viviendo entre los cristianos, por ejemplo maestre Hamete, herrador, posiblemente el arriba mencionado alcalde moro. Se le obligó a retirarse a la morería.

Aún hoy día el tipo de viviendas apiñadas, construidas con entramado de madera con relleno de adobe, revocadas al exterior, unido a una red de calles estrechas, cortas y tortuosas, recuerda palpablemente la situación de la antigua morería arandina ${ }^{26}$.

[Continuará]

${ }^{25}$ Cf. Apéndice 7.

${ }^{26}$ RGS. T. III, $\mathrm{n}^{2} 1.932 ;$ T. IV, nos 2.606 y 2.900; T. VII, $\mathrm{n}^{9} 1262$. 